\title{
DELINEAMENTOS METODOLÓGICOS DA PESQUISA EM EDUCAÇÃO
}

\author{
METHODOLOGY DESIGNS OF RESEARCH IN EDUCATION \\ DISEÑOS METODOLÓGICOS DE LA PESQUISA EN EDUCACIÓN
}

RESUMO: Hoje é notório no currículo da graduação a presença de disciplinas voltadas para o ensino de métodos e técnicas de pesquisa. Tal presença pode ser atribuída à exigência da elaboração da monografia para a conclusão do curso. No âmbito da pós-graduação, aos componentes curriculares de ensino dos fundamentos da pesquisa científica somam-se os de orientação da prática da investigação, a exemplo da disciplina "Trabalho individual orientado". A pesquisa acadêmica, que anteriormente se fazia quase que exclusivamente no espaço da pós-graduacão, conquista seu espaço também na graduação. Este artigo foi motivado para atender aos estudantes que, no contexto das aulas de metodologia da graduação em Pedagogia na Universidade do Estado da Bahia, solicitaram um texto que apresentasse o processo de elaboração do projeto de pesquisa. Uma das funções mais importantes da prática docente do professor universitário é a de orientar e dirigir as atividades de pesquisa dos estudantes. O grande desafio do professor universitário é a formação de um profissional crítico e autônomo que seja capaz de refletir sobre o caminho percorrido durante o próprio caminhar, negando-se a repetir receitas e ter uma práxis reducionista e reiterativa em vez de criativa.

PALAVRAS-CHAVE: Metodologia. Projeto de pesquisa. Percursos teóricos.

ABSTRACT: Nowadays it has been seen in the graduations curriculum the presence of subjects facing the teach of methods and research techniques. This presence may be atributed to the demand of creating a monography to complete the course. In the postgraduation, precisely talking about the components of the curriculum in the foundaments of scientific research teaching, we can increase those about investigation practice orientation, an exemple would be the discipline "Oriented individual work". The academic research, in the past was almost exclusively done in the postgraduation space, gets it space in the graduation. This article had the motivation to attend those students who, in the classes of graduation methodology in pedagogy in "Universidade do Estado da Bahia", asked for a text that would introduce the process of creating a research project. The biggest challenge of the universitary teacher is the formation of a critical and autonomous professional, who would be capable of think about his path through his own walk, denying to just follow recipys and have a reducionalist and repetitive think, instead of a creative one.

KEYWORDS: Methodology. Projeto of research. Theoretical orientations.

RESUMEN: Hoy en día es evidente en el plan de estudios de pregrado de la presencia de cursos dirigidos a los métodos de enseñanza y técnicas de investigación. Esta presencia se puede atribuir a exigir la preparación de la monografía para completar el curso. Como parte de los componentes del plan de estudios de posgrado de los fundamentos de la investigación científica de la educación son, además de la orientación de la práctica de la investigación, tales como la disciplina orientada "trabajo individual". La investigación académica, que previamente se compone casi exclusivamente en el espacio de posgrado, conquistar su espacio demasiado graduación. Este artículo fue motivado para atender a los estudiantes que, en el contexto de las clases de metodología de graduación en pedagogía en la Universidad de Bahía, solicitaron un texto para presentar el proceso de elaboración del proyecto de investigación. Una de las funciones más importantes de la práctica docente del profesor universitario es guiar y actividades de investigación directa de los estudiantes. El gran reto del profesor universitario es la formación de un crítico y autónomos para poder reflexionar sobre el camino recorrido durante el paseo en sí negarse a repetir las recetas tienen una práctica reduccionista y reiterativa en lugar de creativo.

PALABRAS CLAVE: Metodología. Proyecto de investigación. Caminos teoréticos. 


\footnotetext{
* Doutora em Educação pelo PPGE da Faculdade de Educação da Universidade Federal da Bahia (UFBA). Mestre em Educação (FACED-UFBA). Especialista em Filosofia Contemporânea pela Faculdade São Bento da Bahia. Professora Adjunta do Departamento de Educação e do Programa de Pós-Graduação em Educação e Contemporaneidade da Universidade do Estado da Bahia (UNEB).
}

\section{O DESAFIO DA ESCRITA DO PROJETO}

Neste artigo, pretendo apresentar um delineamento sobre o processo de elaboração do projeto de pesquisa com a finalidade de auxiliar os estudantes na escrita de seus projetos. Minha experiência didática como docente na disciplina de "Metodologia da Pesquisa" mostrou-me como pode ser angustiante e penosa, para os estudantes, a tarefa da redação do projeto de pesquisa.

Entendo que a pesquisa científica tem um caráter formativo, fundamental no desenvolvimento do espírito científico e da autonomia intelectual. Principalmente quando se faz referência à formação dos pedagogos e professores, os profundos vínculos entre pesquisar e ensinar nos desafiam a estar constantemente indagando sobre nossa prática docente. Dessa forma, minha intenção, ao escrever este texto, é de caráter didático ao pretender oferecer um suporte para o momento de grande ansiedade de quem, pela primeira vez, lança-se na tarefa da investigação sistematizada e rigorosa.

Este delineamento não deve ser tomado, entretanto, como uma receita, um modelo único com pretensões de ser "o melhor". A advertência de que modelos e padrões propostos podem, ainda que bem intencionados, limitar ou mesmo impedir a expressão da liberdade do pesquisador é, aqui, válida. Justifico a minha apresentação de uma proposta de desenho da estrutura de um projeto para estudantes da graduação em Pedagogia por perceber que o receio que o professor tem de engessar a criatividade dos alunos ao oferecer modelos pode levar, no sentido oposto, ao abandono intelectual e à deriva do pensamento, o que é tão problemático para a formação do pesquisador como o engessamento.

Tenho intuído, a partir da minha prática docente, que o oferecimento de algum suporte inicial pode ser uma alavanca importante para que o estudante se perceba capaz de produzir conhecimento e, dessa forma, ganhe confiança para lançar-se na empreitada da atividade de pesquisa de forma mais autônoma. Considero que as dificuldades encontradas pelo estudante que é deixado completamente sem orientação podem levá-lo a desenvolver uma falsa representação da atividade de pesquisa, o que o levaria a vivenciar experiências frustrantes e dolorosas. Há grande diferença entre o super dimensionamento do caráter formal da pesquisa - quando se exige o cumprimento de um único modelo aceito como o correto - e, no outro extremo, a falta de qualquer orientação. Minha experiência em ensinar a elaborar projetos de pesquisa na graduação me ajuda a apresentar este "roteiro", principalmente para atender à solicitação dos alunos.

\section{O PAPEL DO MÉTODO NA ELABORAÇÃo DO PROJETO}

A primeira questão a ser abordada com os estudantes é a complexidade do conceito de método. Justamente 
porque o método possui dimensões ontológicas, epistemológicas e instrumentais, ele não pode ser despojado de qualquer uma delas sem sofrer um drástico reducionismo. Somente partindo de sua acepção mais superficial, podemos reduzir o método ao seu caráter instrumental. A seguir, apresento uma breve reflexão sobre as dimensões do método: ontológica, epistemológica e instrumental.

\subsection{Método: dimensão ontológica}

É difícil, no espaço deste texto, aprofundar a reflexão sobre a razão ontológica. Entretanto, para o que se propõe este artigo, é suficiente dizer que a dimensão ontológica do método é aquela em que se foca a questão do princípio. $\mathrm{O}$ que foi abstraído, separado mentalmente, precisa ser reconsiderado no âmbito do uno. Conforme nos indica Gilbert (2005, p. 263): "A verdade surge no mesmo momento que o ser do ente se revela ao pensamento. Ela é medida por sua presença no pensamento".

A principal implicação metodológica decorrente desta afirmação é a de que o resultado do conhecimento é sempre mediado pelo método que foi empregado.

Luckács, em seu estudo sobre a ontologia do ser social, afirma como fundamento ontológico de constituição da realidade humana a construção de uma percepção teleológica do mundo. Toda ação tem uma base ontológica, uma vez que: "O modelo do pôr teleológico modificador da realidade, torna-se, assim, fundamento ontológico de toda práxis social, isto é, humana. Na natureza, em contrapartida, só existem conexões, processos etc. causais, nenhum de tipo teleológico" (LUCKÀCS, 2010, p. 45).

O método é compreendido pela razão ontológica como possuindo um componente de percepção dos fundamentos da consciência, construídos dialeticamente pela historicidade e pela teleologia. A consciência produz sentidos, e estes são os motores para as objetivações produzidas pela consciência que se manifestam em diferentes produções: cognitivas, culturais, epistêmicas etc.

A razão ontológica é aquela que busca construir sentidos unindo o que foi fragmentado a fim de compreender a potência que faz surgir o modo de ser do que se manifesta. Dessa forma, as pesquisas que se denominam ontológicas estão preocupadas em compreender que o método de produção do conhecimento é influenciado pela forma de viver, pelo fluxo de sentidos que produz e ceifa sensibilidades produzindo visibilidades e invisibilidades. O método, compreendido como o modo de fazer as coisas, traz em sua dimensão ontológica a necessidade de transcender seu componente instrumental para se produzir o sentido humano.

\subsection{Método: dimensão epistemológica}

A razão epistemológica está relacionada com a teoria do conhecimento. Sua preocupação primordial refere-se à questão das condições de possibilidade do conhecimen- 
to e às formas de raciocínio empregadas nas proposições científicas. Os epistemólogos se interessam por investigar as estratégias de pensamento e as bases conceituais das pesquisas com estatuto científico, a fim de demarcar os limites entre a ciência e outras formas de conhecimento. A pergunta sobre como opera o saber científico e a necessidade de haver ou não adequação da epistemologia às singularidades dos campos de conhecimento, principalmente as que diferenciam ciências humanas das exatas, conhecimentos teóricos dos aplicados, é um ponto crucial de conflito entre os epistemólogos. Os mecanismos de demarcação e as ferramentas lógicas que as sustentariam constituem-se em campos de disputa sobre a questão da legitimidade do saber científico. Neste cenário de disputa epistemológica, o exemplo clássico da defesa de dois lados opostos foi dado pelas ideias do anarquista epistemológico Paul Feyerabend e do defensor do falseacionismo Karl Popper. Ao criticar a formação do cientista, Feyerabend usa os seguintes argumentos:

A educação científica, tal como hoje a conhecemos, tem precisamente esse objetivo. Simplifica a ciência, simplificando seus elementos: antes de tudo define-se um campo de pesquisa; esse campo é desligado do resto da História (a Física, por exemplo, é separada da metafísica e da Teologia) e recebe uma lógica própria. Um treinamento completo nesse tipo de 'lógica' leva ao condicionamento dos que trabalham no campo delimitado; isso torna mais uniformes as ações de tais pessoas, ao mesmo tempo em que congela grandes porções do processo histórico. 'Fatos' estáveis surgem e se mantém, a despeito das vicissitudes da História. Parte essencial do treinamento, que faz com que fatos dessa espécie apareçam, consiste na tentativa de inibir intuições que possam implicar confusão de fronteiras. A religião da pessoa, por exemplo, ou sua metafísica ou seu senso de humor [...] devem manter-se inteiramente à parte de sua atividade científica. Sua imaginação vê-se restringida e até sua linguagem deixa de ser própria. E isso penetra na natureza dos 'fatos' científicos, que passam a ser vistos como independentes de opinião, de crenças ou de formação cultural. (FEYERABEND, 1977, p. 21).

A epistemologia coloca questões à ciência:

É possível conhecer o mundo? Pode o sujeito captar o objeto em toda sua dimensão, isto é, não só o fenômeno, mas também o noumeno, a coisa em si? É capaz o homem de desvendar as leis que regem o universo? Nossa consciência tem a capacidade de refletir de maneira adequada a realidade objetiva? (TRIVIÑOS, 2009, p. 24). 
Neste sentido, podemos identificar diferentes epistemologias, diferentes concepções no que se refere à questão da validade do conhecimento científico: epistemologia positivista, epistemologia fenomenológica e epistemologia marxista.

\subsubsection{Epistemologia Positivista}

Frente à questão da validade do conhecimento científico, como é sabido, o positivismo tem uma premissa fundamental: ater-se aos fatos e, a partir deles, elaborar leis de funcionamento da realidade. Minayo (2004, p. 39) apresenta as teses básicas do positivismo:

- a realidade se constitui essencialmente naquilo que nossos sentidos podem perceber;

- as Ciências Sociais e as Ciências Naturais compartilham de um mesmo fundamento lógico e metodológico, elas se distinguem apenas no objeto de estudo;

- existe uma distinção fundamental entre fato e valor: a ciência se ocupa do fato e deve buscar se livrar do valor.

Percebemos que o conhecimento, dentro dos limites da epistemologia positivista, é marcado pela ideia de inspeção. Questiono frontalmente essa concepção de conhecimento como verificação, como inspeção à realidade feita pela razão objetiva. O positivismo defende a ideia de que a teoria poderia ser comparada a uma lanterna a irradiar luz sobre os fatos. O que o positivismo tem dificuldades de reconhecer é que não existe ponto de vista exterior à História e aos sujeitos. A garantia da objetividade do conhecimento não está relacionada e nem é diretamente proporcional à neutralização da subjetividade. Ao negar a dimensão humana do método, o positivismo sugere que não é somente possível, mas desejável silenciar a subjetividade, associando a qualidade da pesquisa ao seu nível de despersonalização. Nestes termos, a relação estaria colocada entre os meios e o objeto de estudo, pois a ideia básica é que somente quando se elimina a individualidade se está realmente fazendo ciência. Para falar sobre algo com o devido rigor, temos de calar sobre nós mesmos. É ilustrativo, nesse sentido, o enunciado de Heráclito - filósofo pré-socrático -, que no fragmento 50 afirma "Escutando não a mim, mas ao logos, é sábio concordar [homologein] que tudo é um.”

Como se escuta o logos? Que sentidos traz tal evocação? Esta é uma das questões-chave que a fenomenologia pretendeu enfrentar.

\subsubsection{Epistemologia fenomenológica}

Em confronto com a visão objetivista do positivismo, a epistemologia fenomenológica acredita que somente pode haver verdades referidas a horizontes de interpretações históricas e pessoais. A pesquisa é considerada, nessa 
perspectiva, como uma prática social e historicamente contextualizada.

As concepções metodológicas alinhadas às correntes fenomenológicas e existenciais afirmam que o conjunto de experiências de vida de uma pessoa a leva a indagar-se pelo sentido das coisas.

Diversamente do positivismo, que parte da inquirição sobre o que é o fato e que realidades ele institui, a fenomenologia parte da reflexão sobre o que é o ser humano e qual o sentido de seu conhecimento. O foco metodológico está na dimensão do espírito, que constantemente se interroga: o que significa? Nessa perspectiva epistemológica, existe grande diferença de interpretação dos fatos para o positivismo e para a fenomenologia:

Este é um ponto muito importante: existem os fatos? Certamente, existem. Mas não nos interessa os fatos enquanto fatos, interessamo-nos pelo sentido deles. Por isso posso também "colocar entre parênteses" a existência dos fatos para compreender sua essência. [...]. O positivismo considera muito importante os fatos, sobretudo assumidos como tais pelas ciências físicas. No entanto, Husserl diz que os fatos existem e são fatos. Mas o que são? Por exemplo, a ciência física olha a natureza, mas o que são esses fatos? $\mathrm{Ou}$ ainda, as ciências sociais olham a sociedade, mas o que é a sociedade? Qual é seu sentido? Fazemos tantas análises da sociedade sem saber do que se trata. Não basta dizer que existem, e esta é uma das polêmicas de Husserl no confronto com o Positivismo [...] (BELLO, 2006, p. 23).

Enquanto que para o positivismo o homem é "animal racional", para a fenomenologia o homem "é ser dotado de palavra", um ser que interpreta. Para a fenomenologia, a verdade está no sentido, não no fato em si.

A concepção fenomenológica proposta por Husserl representou uma verdadeira revolução epistemológica, ao afirmar o interesse das ciências humanas para a condição perceptiva do pensamento e do conhecimento. Bello (2006) traz um interessante exemplo que transcrevo a seguir com o objetivo de esclarecer a diferença entre fato e sentido do fato. Ela apresenta como objeto que está sendo percebido por determinado sujeito, determinado copo.

Para realizar a análise do sujeito faremos um exercício, comecemos por dizer que estamos diante de um copo d'agua. Vemos, sobre a mesa, o copo que antes já estava lá, podíamos vê-lo, mas não tínhamos prestado atenção nele. Esta é uma coisa interessante que apresenta dois níveis. Antes víamos os copos, mas não fazíamos uma reflexão, talvez porque não estivéssemos com sede. Agora tenho sede e começo a prestar atenção. Estamos refletindo 
um pouco sobre o tema do "ver o copo". Antes estávamos cônscios, sabíamos ter visto o copo sem ter feito uma reflexão a respeito. Todos nós tínhamos uma experiência perceptiva do copo, que estava em nós, dentro de nós. [...] Enquanto estávamos vivendo o ato perceptivo (o ato de ver o copo), poderíamos perguntar do que esse ato era formado. [...] Enquanto coisa física, enquanto existente, onde estava o copo? Estava fora. Porém, enquanto visto, onde estava? Dentro. Temos ai o ato de ver, e enquanto vivemos o ato, estamos vivendo o copo-visto dentro de nós. (BELLO, 2006, p. 27).

Como se pode perceber, para a fenomenologia o método não está dissociado da vida e o conhecimento que é elaborado a partir de sua aplicação está condicionado pela rede complexa de valores, teorias e compromissos do pesquisador. Nessa perspectiva, o enfoque está na interpretação, na construção do sentido que o pesquisador dá aos dados/informações que recolhe. A intencionalidade do pesquisador antecede a percepção do objeto, ou seja, o fenômeno se mostra à determinada consciência a partir das suas experiências e sua visão de mundo.

\subsubsection{Epistemologia marxista}

A epistemologia marxista está embasada numa ontologia materialista, criticando as ontologias da substância. Uma das características fundamentais da epistemologia marxista é a concepção dialética. O mundo não é dotado de substância e está em constante mudança.

Triviños (2009, p. 52) apresenta três características fundamentais da concepção materialista do mundo: a materialidade do mundo, a matéria é anterior à consciência, e, por último, o mundo pode ser conhecido.

Os principais argumentos da epistemologia marxista compreendem, de um lado, o entendimento de que o método científico para o conhecimento da realidade não começa no real simples, ou seja, no real sensível, mas no real como concreto de pensamento, momento que a realidade aparece com todas as suas determinações históricas, e, por outro lado, o entendimento que partir do real como concreto de pensamento significa conceber o objeto de conhecimento não como sendo o real empírico, mas como sendo o real concreto (BORBA; PORTUGAL; SILVA, 2008, p. 13).

Na epistemologia marxista, o real concreto é a práxis humana. Esta é uma atividade singular do ser social. Mas esse ser social também é singular e concreto: os sujeitos históricos. Entretanto, existem interesses contraditórios entre as diferentes classes sociais que determinam posturas políticas fruto de suas concepções de mundo.

A aceitação pelos homens de uma teoria é condição essencial de uma práxis verdadeira, 
mas não é ainda a própria atividade transformadora. É preciso determinar, em primeiro lugar o tipo de teoria que há de ser aceita e que há de passar para a própria realidade: é preciso também determinar o tipo de homens concretos que, uma vez que fazem a sua crítica, a convertem em ação: a crítica há de ser radical. Segunda: os homens chamados a realizar a filosofia, como mediadores entre ela e a realidade, são, em virtude de uma situação particular, os proletários (VÁZQUEZ, 2011, p. 119).

Na epistemologia marxista, o conceito de práxis é estruturante do movimento histórico e uma categoria fundante da forma específica do ser se constituir como humano e social.

\subsection{Método: dimensão instrumental}

A segunda dimensão do método, mas não a menos importante, seria a instrumental. Nessa dimensão, o enfoque está na operacionalização que exige decisões sobre quatro tópicos básicos: quais os tipos de pesquisa a utilizar, quais serão as fontes de informação, quais instrumentos de coleta de dados vão permitir melhor acesso aos dados e que tipo de abordagem é colocada pelo problema: a qualitativa ou a quantitativa. $\mathrm{O}$ recurso ao tipo de abordagem apenas aponta qual o compromisso que o pesquisador assume na relação com o fenômeno que estuda. Sabemos que todo fenômeno possui extensão e densidade e que a separação absoluta entre quantidade e qualidade é questionável. Entretanto, do ponto de vista metodológico, é necessário que o pesquisador defina com o que está se comprometendo para que não seja cobrado pelo que não desejou fazer. Numa das minhas aulas, no diálogo sobre esta questão, um estudante utilizou uma metáfora interessante para ilustrar a abordagem. A imagem que utilizou foi o ato de nadar, associando a dimensão da extensão como sendo aquela que fica na superfície, que apenas nadando teria acesso. Para alcançar a dimensão qualitativa do fenômeno, seria necessário o mergulho, no qual a visão fica mais focada e ao mesmo tempo se pode ver as sutilezas que a superfície omite.

\section{ELABORAÇAO DO TEMA E PROCESSO DE ENFOCAMENTO DO OBJETO DE ESTUDO}

Todo objeto de pesquisa insere-se num contexto mais amplo de preocupações, com diferentes recortes. Podemos dizer que o processo de delimitação do objeto de estudo se aproxima da ideia da moldura, aos poucos, partindo do tema, vai se delimitando o objeto num processo de sucessivos enquadramentos. É como se estivéssemos colocando uma moldura no nosso quadro, definindo e apresentando para o futuro leitor o que fica dentro e o que fica fora, no 
âmbito do nosso trabalho. Uma delimitação bem feita assemelha-se à imagem de um funil, em que se parte do mais geral ao mais específico. Mesmo sabendo que devemos enfocar nosso olhar para produzir uma pesquisa, já que a ideia da pesquisa é justamente produzir um conhecimento especializado, não podemos deixar de situá-lo num espaço maior de preocupações teóricas. Temos de saber o que os outros pesquisadores do mesmo objeto de estudo colocam como problema, que relações é possível fazer etc.

Vejamos o exemplo a seguir.

\section{Tema: Aprendizagem da matemática Delimitação do objeto: O uso da calculadora na aprendizagem da matemática}

Esse objeto de estudo poderia ser abordado por diversas problematizações diferentes. Poderíamos querer saber qual a opinião dos professores de matemática, qual a opinião dos alunos, qual o estado geral das discussões teóricas sobre o tema, que competências e habilidades são exigidas para resolver exercícios propostos em sala de aula etc.

Vamos imaginar que os autores que selecionamos trouxeram esse leque de discussões sobre o uso da calculadora na escola. As questões que trazemos para nos situar no campo de preocupações sobre o nosso tema é o que definimos como problemática. Fica evidente, portanto, que a qualidade da problemática está relacionada com a qualidade das leituras que fazemos. Como não podemos aprofundar nossa pesquisa sobre todas as questões da problemática que levantamos, o próximo passo é definir qual dessas questões nos mobilizam para a pesquisa.

\section{DANDO INÍCIO À CONSTRUÇAO DO PROBLEMA}

Uma das maiores dificuldades dos estudantes nos semestres iniciais é compreender que um problema de pesquisa é diferente de um "problema" compreendido no senso comum. Os problemas científicos devem ser formulados de forma adequada, e esta pode ser "sentida" se o problema "pedir" certo delineamento metodológico que permita a construção de sua resposta.

Os problemas mal formulados não têm consequências metodológicas justamente porque não colocam uma questão científica, se limitando a uma mera opinião. Para ilustrar, vamos imaginar que um estudante esteja interessado em investigar o tema da violência na escola. Se ele perguntar: "Deveria ter violência dentro da escola?", a resposta se esgota na opinião de "sim" ou "não". Um problema bem formulado colocaria relações entre "variáveis" percebidas no processo de estudo sobre o tema. Por exemplo: "As escolas de periferia realmente são mais violentas que as escolas de classe média”? 
"Existem violências específicas dirigidas a meninas ou meninos?" Nessas perguntas, aparece a necessidade de aprofundar relações entre diferentes formas de violência, ou seja, é necessário conceituar, categorizar, produzir redes conceituais que possam explicar o fenômeno.

Todo problema tem também um conceito estruturante que necessita ser definido e trabalhado de forma coerente em todo o trabalho. No exemplo anterior, precisaríamos definir o que é violência, se existe uma violência propriamente escolar etc.

Vamos pensar num outro exemplo em que o problema seja "Quais são os pressupostos básicos nos programas de promoção da paz desenvolvidos nas escolas públicas municipais de ensino fundamental de Salvador?" Nesse caso, o conceito estruturante do problema é a paz. Qual seria o conceito de paz que assumiríamos para analisar os ditos programas? Podemos compreender paz como ausência de conflitos ou como uma forma não violenta de resolver os conflitos. No primeiro caso, estaríamos assumindo uma visão purista e artificial das relações humanas que poderia estar de acordo com o conceito dos programas ou não. No segundo caso, estaríamos assumindo um conceito mais realista e o que buscaríamos é a paz que é fruto do diálogo, das concessões, da tolerância, da negociação constante de sentidos. Esse referente teórico, a partir do qual vamos compor nosso quadro analítico, também é método.

\section{DEFINIÇÃO DOS OBJETIVOS DO ESTUDO}

A construção dos objetivos também aparece como grande dificuldade na elaboração de projetos. Poderíamos definir os objetivos como metas a atingir, ou seja, são ações parciais que, no seu conjunto permitiram construir a resposta do problema. Os objetivos podem ser classificados, no que se refere à sua extensão, em gerais e específicos. Os gerais dizem respeito às metas amplas do estudo que podem ser subdivididas em metas parciais. Para ilustrar, vamos retomar o exemplo já apresentado do tema "violência na escolar".

Problema: Quais são os tipos mais frequentes de violência escolar nas escolas municipais de Salvador no ano de 2014 e suas possíveis causas?

Geral: Construir um diagnóstico dos tipos de violência escolar.

\section{Específicos:}

- Identificar os tipos de armas que os alunos levam para escola.

- Verificar se existe relação entre uso de drogas e práticas violentas.

- Verificar a existência de programas de prevenção à violência na escola

- Levantar a opinião dos professores sobre as causas da violência etc. 
Observa-se que os objetivos são metas construídas que permitam análise do fenômeno que está sendo investigado. Portanto, um bom projeto de pesquisa apresenta articulações consistentes entre os objetivos e o problema investigado.

\section{LEVANTAMENTO DAS HIPÓTESES OU SUPOSIÇÕES}

As hipóteses ou suposições são respostas antecipadas ao problema. Quando se coloca uma pergunta, tem-se uma ideia das possíveis respostas. O papel das suposições é indicar possíveis caminhos de resolução do problema.

Problema: Quais são os tipos mais frequentes de violência escolar nas escolas municipais de Salvador no ano de 2014 e suas possíveis causas?

Hipótese: Supomos que os tipos de violência escolar mais frequentes são agressões físicas e são causadas por uso de drogas.

\section{ELABORAÇÃO DA JUSTIFICATIVA.}

A justificativa é o momento em que o pesquisador apresenta a relevância do estudo que está propondo, sua contribuição para ampliar a compreensão do fenômeno e sua aplicação. Dando continuidade ao exemplo que estamos utilizando, teríamos:

Problema: Quais são os tipos mais frequentes de violência escolar nas escolas municipais de Salvador no ano de 2014 e suas possíveis causas?

Justificativa: Este estudo pretende contribuir na identificação dos possíveis obstáculos intraescolares para que se efetive uma educação para a cidadania e respeito ao outro a partir do reconhecimento de que o ambiente escolar pode funcionar como caixa de ressonância em relação à comunidade local.

\section{MÉTODO}

$\mathrm{Na}$ apresentação da metodologia, definimos as filiações teóricas e epistemológicas que formaram nosso olhar de pesquisador e que vão embasar nossas categorias interpretativas e analíticas. No cenário teórico atual, emergem como principais paradigmas os modelos chamados "paradigmas normativos, ou lineares" e os "paradigmas complexos, ou interpretativos".

Os paradigmas normativos apoiam-se nos pressupostos do positivismo cuja ideia de cientificidade está amparada na lógica formal. Os paradigmas interpretativos baseiam-se no pressuposto de que os objetos de pesquisa são, antes, construções do que manifestações da realida- 
de tal como ela essencialmente é. Conforme aponta Demo (1995), conceber o objeto como construção significa problematizar a relação sujeito-objeto. A relação do sujeito com o objeto não é da descrição pura, mas de diálogo, uma vez que a realidade nunca é tomada como algo preexistente e exterior ao sujeito.

Nossas opções epistemológicas têm de estar claras e coerentes com os instrumentos que escolhemos para interpretar a realidade. O que fazemos, conforme apontou $\mathrm{Ru}-$ bem Alves (2000), é montar armadilhas para capturar os fenômenos, logo, se pretendemos pegar um leão seria inócuo montar uma armadilha para coelho.

As "armadilhas" da pesquisa científica compõe-se de elementos como:

a) instrumentos de coleta de dados (questionários, entrevistas, formulários, observação);

b) tipos de pesquisa: (estudo de caso, pesquisa-ação, pesquisa de campo, pesquisa experimental, pesquisa descritiva, pesquisa bibliográfica, pesquisa documental etc.);

c) fontes de informação: pessoas, documentos, livros, artigos;

d) natureza da abordagem do fenômeno: o interesse do pesquisador está voltado para a dimensão da extensão (quantitativa) ou da densidade (qualitativa) do fenômeno?

\section{AVALIE O SEU PROJETO}

Sintetizando os conteúdos trabalhados neste artigo, apresentamos um chek-list como auxílio para que os estudantes avaliem a qualidade de seus projetos.

\begin{tabular}{|l|l|}
\hline 1. Título & $\begin{array}{l}\text { Esclarece as intenções do investigador apontando o } \\
\text { problema formulado e a forma de abordá-lo? }\end{array}$ \\
\hline 2. Introdução & $\begin{array}{l}\text { Apresenta o processo de delimitação do tema e à definição } \\
\text { do problema? Apresenta suporte teórico para a problemática } \\
\text { apresentada? }\end{array}$ \\
\hline 3. Objetivos & $\begin{array}{l}\text { São metas a atingir no estudo? Estão coerentes com o } \\
\text { problema? }\end{array}$ \\
\hline 4. Justificativa & Apresenta a contribuição, a relevância do estudo? \\
\hline 5. Metodologia & $\begin{array}{l}\text { É adequada ao problema e aos objetivos? Permite ser } \\
\text { coerente com as variáveis indicadas no problema? Indica } \\
\text { fontes de informação pertinentes aos objetivos? }\end{array}$ \\
\hline 6. Formatação & $\begin{array}{l}\text { Todos os elementos pré-textuais, textuais e pós-textuais } \\
\text { estão completos e em ordem? }\end{array}$ \\
\hline 7. Referências & $\begin{array}{l}\text { Todos os autores citados no corpo do texto estão presentes } \\
\text { na lista de referências? As referências trazem todos os } \\
\text { elementos bibliográficos necessários à sua localização? }\end{array}$ \\
\hline
\end{tabular}

\section{REFLEXÃO FINAL}

A escrita do projeto de pesquisa é o momento de sistematização e objetivação do pensamento que, ao ter sido capaz de se apropriar de "lentes" teóricas, constrói sentidos 
para as perguntas que elabora. Dessa forma, fica claro que a complexidade e o rigor do pensamento são condicionantes para a qualidade da boa pergunta, que é o elemento estruturante do projeto.

As várias dimensões do método abordadas neste artigo intencionaram destacar a complexidade da produção de conhecimento. Do ponto de vista da racionalidade ontológica, há, no processo de produção do conhecimento, uma itencionalidade emergente dos fios existentes entre o pesquisador, o tema, os seus objetivos e as implicações subjetivas que determinam sua visão de mundo. O saber científico, não sendo neutro, se constitui por dimensões ontológicas, ainda que não sejam reconhecidas por determinadas epistemologias.

A dimensão ontológica do conhecimento se dirige às perguntas essenciais, ou seja, que dizem respeito à natureza do ser que determinado conhecimento produz. Tomando como exemplo nossa área de trabalho, a Educação, a preocupação ontológica pode ser explicitada nos argumentos a seguir:

[...] Cuando decimos que la educación debe preparar "para la vida" queremos decir que debe preparar para 'ganarse la vida' y para 'sobrevivir' de la mejor forma posible em um 'entorno vital' (entendido como uma especie de nicho ecológico) cada vez más complejo. En estas condiciones, es claro que la mediación entre el saber y la vida no es outra que la apropiación utilitaria del saber em relación com las necesidades de la vida o, ló que es ló miesmo, com las necesidades del Mercado y lós fines del Estado. (LARROSA, 1997, p. 34).

A dimensão ontológica do método não omite as implicações humanas do investigador por acreditar que são precisamente essas que permitem o envolvimento político, no sentido amplo, com a vida, ou seja, com a radicalidade das consequências humanas da sua aplicação. Nessa dimensão, produzir conhecimento é produzir vida. A vida não pode ser reduzida a objeto de investigação, ela é antes fonte ontológica para o pensamento consequente. Nessa linha de pensamento, conforme nos aponta Larrosa (1997), as epistemologias alinhadas ao paradigma linear ou instrumental são capazes, sem dúvida, de explicar e analisar a estrutura e o funcionamento da realidade natural e social, entretanto elas não têm compromisso emancipatório justamente porque se descomprometem com a dimensão ética e ideológica da realidade humana.

Ao elaborar o projeto de pesquisa, o estudante é convocado, antes de tudo, a tomar posição e inscrever-se em um campo de disputa de sentido sobre o que significa o conhecimento humano. Tal posição requer coerência entre ser sujeito e ser pesquisador. Tornar-se um pesquisador é ter consciência dos compromissos que tal função social traz, é ser capaz de, no plano teórico, analisar os 
diferentes sistemas de pensamento no qual se situa seu tema de interesse, e, no plano prático, objetivar sua teorização em compromissos de mudança social.

\section{REFERÊNCIAS}

ALVES, Rubem. Filosofia da ciência: introdução ao jogo e suas regras. São Paulo: Brasiliense, 1982.

BORBA, Siomara; PORTUGAL, Adriana Doyle ; SILVA, Sergio Rafael Barbosa da. Pesquisa em educação: a construção teórica do objeto. Ciências \& Cogniçãa, v. 13, p. 12-20, 2008.

DEMO, Pedro. Metodologia científica em ciências sociais. 3. ed. São Paulo: Atlas, 1995.

GATTI, Bernardete Angelina. A construção da pesquisa em educação no Brasil. Brasília: Plano, 2002.

LARROSA, Jorge. Saber y educacición: a educação e o problema do conhecimento. Educação \& Realidade, v. 22, n. 1, jan./jun, p. 33-55, 1997.

LUKÀCS, Gyoegy. Prolegômenos para uma ontologia do ser social. São Paulo: Boitempo, 2010.

MEKSENAS, Paulo. Pesquisa social e ação pedagógica: conceitos, métodos e práticas. São Paulo: Loyola, 2002.

MINAYO, Maria Cecília de Souza. O desafio do conhecimento: pesquisa qualitativa em saúde. 8. ed. São Paulo: Hucitec, 2004.

MOROZ, Melania et al. O processo de pesquisa: iniciação. Brasília: Plano, 2002.

TRIVIÑOS, Augusto N. S. Introdução à pesquisa em ciências sociais: a pesquisa qualitativa em educação. São Paulo: Atlas, 2009.

VÁZQUEZ, Adolfo Sánchez. Filosofia da práxis. 2. ed. São Paulo: Expressão Popular, 2011.

VERGARA, Sylvia Constant. Projetos e relatórios de pesquisa em administração. São Paulo: Atlas, 1997. 